\title{
A POLÍtTICA DA EXTENSÃO COMO PEDAGOGIA DA SENSATEZ: A \\ UNIVERSIDADE DESPERTADA
}

\section{The politics of the extension as the pedagogy of wisdom: the awaken university \\ La política de la ampliación en pedagogía de la razón: la universidad de despertó}

\author{
Alberto Damasceno ${ }^{1}$ \\ Emina Santos ${ }^{2}$ \\ Ney Cristina Oliveira ${ }^{3}$ \\ Patrícia Souza ${ }^{4}$ \\ Vanessa Costa $^{5}$
}

RESUMO

\begin{abstract}
Trata o presente artigo de análise das concepções de extensão presentes na história do ensino superior brasileiro, destacando a vertente do assistencialismo, majoritária até meados da década de 1990, e a versão mais recente, baseada em ressignificações das relações entre universidade e sociedade a partir de um caráter mais interventivo e sustentável. Importa dizer que, compreendida no passado com forte sentido assistencialista, a extensão universitária passou a ser entendida mais recentemente como um processo baseado numa relação transformadora entre a universidade $e$ a sociedade. Isso tem particular importância em um país como o Brasil, cuja significativa dívida social se acumulou durante séculos, construindo um cenário que não apresenta solução a curto e médio prazo. Essa realidade tem imposto a suas instituições e cidadãos, com justificada urgência, um amplo debate sobre como construir adequadamente a cicatrização de suas profundas chagas sociais e o equilibrio de oportunidades de desenvolvimento humano para todos, ficando evidente que a consciência da diversidade, como valor positivo e emancipatório, é apenas o primeiro passo para a inclusão social. Para além da consciência, é preciso envidar esforços que consigam promover a construção de uma democracia racial real, com iguais condições e oportunidades para todos, em especial os afro-brasileiros, cuja "invisibilidade" e quase inexistência nas instituições de educação superior é prova inconteste da necessidade de reverter esse quadro de perversa seletividade. A esperança tem razão de ser, pois, se por vários anos a academia entendeu a extensão apenas como uma forma de prestação de serviços à sociedade, com enfoque em seu caráter assistencialista, depois de muitos debates e experiências acumuladas, esse conceito está mudando. Hoje, extensão é, principalmente, troca de saberes entre a academia e a sociedade. É, portanto, um processo de aprendizagem mútua.
\end{abstract}

Palavras-chave: pedagogia; ensino superior; extensão universitária.

\footnotetext{
ABSTRACT

This article brings an analysis of the concepts of extension in the Brazilian graduation history, highlighting the social welfare work, which was the majority until the middle of 1990s, and the recent version based

1 Professor do Instituto de Ciências da Educação, Diretor de Assistência Estudantil da Pró-Reitoria de Extensão da UFPA. E-mail: alverto@ufpa.br

2 Professora do Instituto de Ciências da Educação, Diretora de Programas e Projetos da Pró-Reitoria de Extensão da UFPA. E-mail: emina@ufpa.br

${ }^{3}$ Professora do Instituto de Ciências da Educação, Pró-Reitora de Extensão da UFPA. E-mail: neycmo@ufpa.br

4 Aluna do Curso de Pedagogia da UFPA, bolsista da Pró-Reitoria de Extensão. E-mail: patriciass@ufpa.br

${ }^{5}$ Aluna do Curso de Pedagogia da UFPA, bolsista da Pró-Reitoria de Extensão. E-mail: nessa@ufpa.br
} 
on new meanings related to the relationship between university and society, from a more interceptive and sustainable character. It is important to state that, compared to what was seen in the past, with a strong social welfare sense, more recently, the extension in the university passed to be seen as a process based on a changing relationship between the university and society. This has a particular importance in a country like Brazil whose significant social debt was accumulated over centuries, building a scenario which does not show solution in short or medium time span. This reality has imposed, on institutions and citizens, with justified urgency, a broad debate on how to properly heal the deep social wounds and have even balanced human development opportunities distribution for all, being obvious that the awareness of diversity as a positive and libertarian value is the first step towards social inclusion. Beyond the awareness, efforts are necessary in order to promote the construction of a real racial democracy, with equal conditions and opportunities for all, especially the African-Brazilians, whose "invisibility" and almost absence in the graduation institutions is an undeniable proof of the need to reverse this perverse selective scenario. The hope has its place because, if for several years, the academy understood extension only as a way to provide services to the society, focusing its social welfare character, after many debates and accumulated experiences, that concept is changing. Today, the main extension's focus is an exchange of knowledge between the Academy and Society. It is, therefore, a process of mutual learning.

Keywords: pedagogy; higher education; university extension.

\section{RESUMEN}

Este artículo de la presente análisis de los conceptos de la extensión actual de la historia de la educación superior brasileña, destacando el caso de la asistencia social, la mayoría hasta la semana a mediados de 90 y y la última versión sobre la base de reformulación de la relación entre la universidad y la sociedad de un carácter mayor sustentável.Importa decir y decir que, entendida en el pasado con un fuerte sentido de bienestar de la educación continua se ha convertido más recientemente, entendida como un proceso basado en la transformación de una relación entre la universidad y la sociedad. Esto es particularmente importante en un país como Brasil, donde la deuda social acumulada durante siglos importantes la construcción de un escenario que no tiene solución en el corto y mediano plazo. Esta realidad ha impuesto sus instituciones y los ciudadanos, la urgencia justificada, un amplio debate acerca de cómo construir adecuadamente la curación de sus profundas heridas sociales y equilibrar las oportunidades de desarrollo humano para todos, claro que la conciencia de la diversidad como algo positivo y emancipadora es sólo el primer paso hacia la inclusión social. Aparte de la conciencia, se deben hacer esfuerzos que pueden mejorar la construcción de una democracia racial real, en igualdad de condiciones y oportunidades para todos, especialmente los afrobrasileños, cuya "invisibilidad" y prácticamente no hay instituciones de educación superior es una prueba convincente la necesidad de corregir esta selectividad perversa. La esperanza es de lamentar porque, desde hace varios años, la academia tiene la extensión solamente como un servicio a la sociedad, centrándose en la asistencia social, después de muchos debates y experiencias acumuladas, este concepto está cambiando. Hoy en día, la extensión es principalmente un intercambio de conocimientos entre el mundo académico y la sociedad. Por tanto, es un proceso de aprendizaje mutuo.

Palabras clave: pedagogía; la educación superior; la extensión universitaria.

\section{A extensão nas universidades brasileiras}

As ressignificações das relações entre estado, sociedade civil e mercado presentes na dinâmica de organização político-administrativa do território nacional a partir da década passada geraram a exigência de novos posicionamentos por parte de suas instituições, com a finalidade de incluir e dar visibilidade a grupos sociais tradicionalmente excluídos dos cenários de par- ticipação da vida pública brasileira.

Na lógica de institucionalização de um novo contrato social que agregue novos protagonistas e novas demandas sociais, as universidades públicas brasileiras assumiriam, como missão originária, a organização de redes dialogais com setores da sociedade, na perspectiva da produção de novos saberes capazes de qualificar a vida das populações da região amazônica.

É importante ressaltar que, nesse nesse contexto, a atividade da extensão universitária 
adquiriu maior significado, pois é potencialmente capaz de maximizar as condições para a participação da universidade pública na elaboração das políticas de Estado voltadas para a maioria da população, bem como para sua constituição em organismo legítimo no controle social da implantação de tais políticas.

Altera-se a dimensão e a substância das ações extensionistas universitárias para além de políticas assistencialistas, elemento que estruturou a existência de tal atividade como tripé da missão institucional da universidade, qualificando-a como processo acadêmico definido e efetivado em função das exigências da realidade, indispensável na formação do aluno, na qualificação do professor e no intercâmbio com a sociedade.

$\mathrm{O}$ entendimento do salto de qualidade exercido por essas atividades carece de argumentação teórico-conceitual para que não transpareça a sensação de naturalização das atividades humanas a partir de determinismos sem substância e, dessa forma, possa ser resgatada a importância histórica da extensão na construção de uma universidade sustentável.

Os primeiros documentos que tratam da questão de extensão nas universidades brasileiras datam do início dos anos 30 do século passado. $\mathrm{Na}$ "Exposição de motivos sobre a reforma das universidades brasileiras", de abril de 1931, a "extensão universitária se destina a dilatar os benefícios da atmosfera universitária aqueles que não se encontram diretamente associados à vida da universidade". Em outro documento, do mesmo ano, os cursos de extensão universitária eram "destinados a propagar, em benefício coletivo, a atividade técnica e científica dos institutos universitários".

A ambiguidade da expressão "benefício coletivo" permite questionar o compromisso social da política de extensão das universidades brasileiras à época. Permite, também, concluir que a diretriz de um assistencialismo difuso, mas direcionado concreta e ideologicamente, nunca esteve tão bem explicitada como no Estatuto das Universidades Brasileiras datado de 1931.

O golpe de 1937 e a ditadura Varguista estenderam suas marcas até o final dos anos 1960. Durante quarenta anos os documentos trataram a extensão universitária de forma secundária, acessória ou simplesmente não trataram.

A extensão, definida como um dos objetivos-fins da universidade brasileira e institucionalizada de forma sistemática e oficial no interior da academia, foi produto da Reforma Universitária de $1968^{6}$, marco normativo que estabelece que "as universidades e as instituições de ensino superior estenderão à comunidade, sob forma de cursos e serviços especiais, as atividades de ensino e os resultados da pesquisa que lhe são inerentes".

Anteriormente à Reforma, as experiências que poderiam caber dentro desse espectro de preocupação representavam iniciativas isoladas, geralmente assistemáticas, quando não episódicas, limitadas por um contexto histórico no qual a universidade, quando muito, era vista como uma boa escola de terceiro grau, formadora de quadros profissionais educados dentro de padrões culturais e técnicos importados dos centros mais dinâmicos do mundo capitalista ocidental, particularmente Estados Unidos, França e Inglaterra.

Entretanto, as ambiguidades ou desatenções das políticas públicas para as atividades de extensão não lograram impedir que algumas experiências socialmente compromissadas ${ }^{7}$ existissem à sombra ou à margem das universidades brasileiras ao longo desses anos.

\footnotetext{
${ }^{6}$ Por meio do artigo 20 da Lei ${ }^{\circ} 5.540$, de 28 de novembro de 1968.

${ }^{7}$ Algumas vivências não podem passar desapercebidas, dentre elas: o Movimento da Cultura Popular, os CPCs (Centros de Cultura Popular, ativados pela UNE), a campanha "De pé no chão também se aprende a ler", o Movimento de Educação de Base (MEB), o Serviço de Extensão Rural da UFPE, a Universidade Volante (da UFPR) e, até um certo momento, o Centro Rural Universitário de Treinamento e Ação Comunitária (Crutac) são experiências que representavam vertentes ideológicas diferenciadas dentro da academia.
} 
Essas divergências quanto ao papel que a universidade deveria cumprir no interior de uma sociedade periférica e dependente acirraram-se com o golpe de 1964. A partir daí, as atividades de extensão foram canceladas tal como eram e assimiladas e retrabalhadas pelas reformas introduzidas em 1968, quando passou a predominar no espaço universitário a concepção de extensão como "prestação de serviços", a exemplo de instituições norte-americanas, a reboque dos acordos MEC-Usaid ${ }^{8}$.

No que tange à UFPA, a introdução do seu Plano Diretor de Extensão para 1976-1979 não só revela a percepção dessas diferenças como sugere caminhos para a sua "correção". $\mathrm{O}$ assistencialismo e a descontinuidade, como características das atividades extensionistas das universidades brasileira, se reproduzem na nossa universidade desde sua fundação, em 1957, até a criação do Crutac $^{9}$, em 1972. Tendo como origem, em sua maioria, os Departamentos dos Centros de Exatas e de Saúde e como destino a população da cidade de Belém, a extensão na UFPA variava das prestações de serviços técnicos a entidades públicas e privadas até o atendimento odontológico às comunidades da capital do estado. Em menor escala ocorreram atividades oriundas das áreas de ciências humanas e socioeconômicas e na área cultural.

Com o advento da reforma universitária e a criação da Sub-Reitoria de Assuntos de Extensão e Natureza Estudantil, a UFPA deu início a uma série de medidas de caráter administrativo com o objetivo de oferecer aos agentes de extensão condições para um trabalho mais integrado, interdisciplinar e homogêneo, do ponto de vista institucional.

A partir dos anos 1980, o foco das atividades de extensão se deslocou para o atendimento de propostas mais "regionais", voltadas para as necessidades que emergissem da própria comunidade. Mesmo após a realização do I Seminário e Extensão da Amazônia - articulado e coordenado pela UFPA - no qual se detectou uma nova retórica extensionista, foram poucas as propostas estruturadas de forma participativa. Entretanto, uma das maiores demonstrações do poder transformador da extensão universitária na UFPA foi dada a partir da implantação dos campi no interior do estado, fator estruturante no dimensionamento multicampi da universidade $e^{10}$.

\section{A extensão universitária como objeto de gestão: desafios e possibilidades na UFPA}

Na Universidade Federal do Pará, instituição foco deste artigo, esse novo marco impactou de forma positiva a reorganização das ações extensionistas como integrantes de uma política institucional, referenciando-se em diretriz de gestão democrática e participativa, indicador social de qualidade acadêmica, eixo que possibilita a flexibilização curricular de seus cursos, bem como indica o orçamento público e financiamento das atividades de extensão.

\footnotetext{
${ }_{8}^{8}$ Foram acordos produzidos nos anos 1960 do século passado, entre o Ministério da Educação do Brasil (MEC) e a United States Agency for International Development (Usaid). Tais acordos visavam a garantir assistência técnica e cooperação financeira à educação brasileira em seus diferentes níveis. O período que foi de junho de 1964 e janeiro de 1968 foi o de maior intensidade nos acordos, tendo sido firmados nada menos que doze deles.

9 O Centro Rural de Treinamento e Ação Comunitária (Crutac), junto com o Centro Universitário de Treinamento Urbano (Ceutur), foi responsável pela integração universidade/comunidade. Além disso, o Crutac inaugurou a presença da UFPA no interior do estado sob condições efetivas e contínuas.

${ }^{10}$ Foi a partir de ações de assistência à saúde da população e de ações de ensino - que remontam mais frequentemente à década de 1950 - que a instituição percebeu a necessidade de se estabelecer formalmente em outras cidades do Pará já nos anos 1980. Antes de serem concebidas no conjunto de uma política de extensão, as atividades sofreram o impacto das variações no conceito de extensão universitária ocorridas em todo o país. Ganharam marcos regulatórios e atualmente são estimuladas a estar cada vez mais aliadas à pesquisa e ao ensino e a provocar novamente mudanças nas instâncias acadêmicas. 
Mais recentemente, em 2006, a política de extensão foi regulamentada no novo Estatuto e Regimento da Universidade, alcançando uma condição definitiva para a vida acadêmico-institucional e para a própria relevância social da presença da UFPA na Amazônia paraense. Nessa lógica, a extensão universitária passou a ser consolidada institucionalmente como "processo educativo, cultural e científico que articula o ensino e a pesquisa de forma indissociável e viabiliza a relação transformadora entre a universidade e a sociedade".

Outro aspecto de grande importância no novo ordenamento jurídico da UFPA em relação às suas atividades de extensão refere-se à concepção e gestão das políticas de ações afirmativas e dos programas de assistência estudantil da instituição. A essência dessa tarefa se materializa em um conjunto de atividades voltadas à emancipação e promoção dos seus estudantes em situação de vulnerabilidade socioeconômica, com dificuldades de acesso, permanência e êxito em sua graduação.

O tema se reveste de grande relevância e atualidade, uma vez que estudos têm comprovado que a pobreza e a miséria em nosso país não são resultantes apenas da escassez de recursos, mas são fenômenos que, na verdade, refletem o perverso padrão de distribuição da renda, sobretudo porque, além de elevada, a desigualdade no Brasil tem demonstrado uma impressionante rigidez.

Dono de uma significativa dívida social que se acumulou durante séculos, o Brasil é um país de índices desproporcionais quando se trata da socialização de suas riquezas. Esse quadro, que não apresenta solução a curto e médio prazo, tem imposto a suas instituições e cidadãos, com justificada urgência, um amplo debate sobre como construir adequadamente a cicatrização de suas profundas chagas sociais e o equilibrio de oportunidades de desenvolvimento humano para todos.

No âmbito das universidades, essa discussão é tão fundamental quanto o tema dos currículos ou dos projetos pedagógicos dos cursos, pois parte significativa de nossos alunos não logrará êxito em sua carreira se não the forem proporcionadas as condições objetivas para tal. Do contrário, gerar-se-á o perverso quadro da retenção acadêmica, que é prejudicial para eles e para o país como um todo. O próprio Secretário de Educação Superior do Ministério da Educação (Sesu/MEC), Ronaldo Mota, ao tratar da importância do Ensino Superior, defendeu que a expansão, além de ser balizada em critérios de qualidade, deve levar em conta a inclusão social. Para a Sesuweb ${ }^{11}$, revista eletrônica da Sesu, ele declarou que é importante crescer com qualidade e é importante, também, que nesse processo se promova a inclusão social por meio da educação.

\section{A questão racial e a comunidade acadê- mica na UFPA}

Dizer que a vida é mais difícil para os desvalidos não é nada original. A novidade é que isso pode adquirir dimensões notáveis quando se trata da educação superior, sobretudo porque os problemas iniciam logo na preparação para o acesso. As informações divulgadas comprovam que mais da metade $(54,3 \%)$ dos estudantes que frequentam as universidades públicas pertencem à parcela dos $20 \%$ mais ricos da população brasileira. Na rede particular a diferença também é elevada. Lá os ricos são maioria, com $64,2 \%$ dos estudantes, e, entre os $20 \%$ mais pobres, $1,8 \%$ estão nas instituições públicas, ao passo que $1 \%$ conseguiu se matricular nas particulares.

Sem cair no lugar-comum da crítica aos métodos ultrapassados e aos conteúdos tradicionais dos programas, basta dizer que a internet, o principal meio de informação nos dias de hoje, ainda é altamente excludente, sobretudo no que diz respeito ao Pará, que ocupa o $4^{\circ}$ lugar no ranking dos sete piores estados brasileiros em

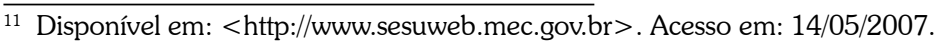


termos de inclusão digital, superando apenas Alagoas, Piauí e Sergipe.

O Mapa da Desigualdade Digital no Brasil, divulgado pelo Ministério da Educação a partir de setembro de 2009 revela que, em nosso estado, só $4 \%$ da população tem acesso à rede mundial de computadores, índice bem abaixo da média da região, que é de 4,9\%. Para se ter uma ideia da magnitude do problema, o Amapá, estado menor e mais pobre, apresenta um índice de $8 \%$ da população que utiliza computador e internet.

Também nesse tema a questão das diferenças sociais se manifesta de maneira violenta. Entre os $40 \%$ mais pobres, somente 3\% usam internet (a média da região é de 3,4\%). Por outro lado, entre os $10 \%$ mais ricos, este índice sobe para $46 \%$, ainda assim abaixo da média do Norte, que é de $49 \%$. Se utilizarmos o critério da etnia, a inclusão digital chega a $17 \%$ da população branca e a apenas $9 \%$ da população negra paraense.

No âmbito educacional, os índices paraenses são ainda mais preocupantes. Conforme o mapa, nas escolas públicas do ensino fundamental que têm computador para uso dos alunos, entre os estudantes classificados como mais pobres, somente $1 \%$ utiliza a máquina, por motivos que vão do desconhecimento até a intimidação diante do equipamento, passando pela simples falta de vontade de fazê-lo. A maior parte desses motivos nasce de apenas um: a falta de computador em casa. Já entre os alunos de famílias mais bem posicionadas economicamente, a utilização do PC sobe para 6,6\%. Depois de tudo isso, é quase insano falar de igualdade de oportunidades entre os candidatos a uma vaga nas universidades.

Formada por diferentes etnias e povos, a sociedade brasileira é plural e com características culturais bastante diversificadas. Todavia, apesar do reconhecimento dessa diversidade e da existência de um "apartheid" social ainda vigente em nosso meio, ainda convivemos com índices que comprovam a ausência de democratização plena das oportunidades econômicas, sociais, políticas e educacionais para a maioria dos brasileiros. Desde sua fundação, o Brasil ainda não foi capaz de pagar a enorme dívida social para com os membros de um de seus grupos fundadores: os negros.

Numa pesquisa realizada recentemente pelo Instituto de Pesquisa Aplicada (Ipea) acerca das condições de vida da população afro-descendente, é possível constatar que, no Brasil, a pobreza está, em grande parte, relacionada à cor da pele. Os negros, que em 1999 representavam $45 \%$ da população brasileira, correspondiam a $64 \%$ da população pobre e $69 \%$ da população indigente. Os brancos, por sua vez, representavam $54 \%$ da população total, com $36 \%$ pobres e $31 \%$ indigentes. $\mathrm{O}$ quadro a seguir demonstra claramente essa triste realidade.

\begin{tabular}{|c|c|c|}
\hline \multicolumn{3}{|l|}{ BRASIL DIVIDIDO } \\
\hline Dependendo da cor o país pode ser bem & Negrose & $\mathrm{Br}$ \\
\hline Porcentagem da população & $46 \%$ & 54 \\
\hline Renda per capita média & 205 reais & 48 \\
\hline Taxa de analfabetismo & $18 \%$ & 8 \\
\hline Média de anos de estudo & $47 \%$ & 6 \\
\hline \multicolumn{3}{|l|}{ Status do emprego em relação ao dos pais } \\
\hline Ascendente & $43.9 \%$ & 52 \\
\hline Tgual & $426 \%$ & 33 \\
\hline Descendente & $14,4 \%$ & 13 \\
\hline \multicolumn{3}{|l|}{ Probabilidade de. } \\
\hline ... ser pobre & $48 \%$ & 22 \\
\hline ... ser desempregado & $7 \%$ & 6 \\
\hline ... não ter carteira assinada & $17 \%$ & 12 \\
\hline ... ser empregador & $3 \%$ & 7 \\
\hline
\end{tabular}

Fonte: Ipea, 2003. 
Nas maiores empresas do país, apenas $1,8 \%$ dos cargos de diretoria são ocupados por negros, $9 \%$ por mulheres e $1 \%$ por pessoas com deficiência. Mais do que mostrar como ainda é pequena a presença de grupos importantes da sociedade brasileira nos cargos mais altos, os dados refletem a falta de diversidade no ambiente profissional. Essas e outras informações foram coletadas a partir de questionários enviados aos presidentes das 500 maiores empresas do Brasil $e$ incluídas no relatório "Perfil social, racial e de gênero das 500 maiores empresas do Brasil e suas ações afirmativas", lançado em dezembro de 2003 pelo Instituto Ethos de Empresas e Responsabilidade Social e parceiros.

De posse desses dados, não é difícil perceber a conformação de uma vergonhosa pirâmide social com um perfil baseado nas tonalidades da pele, em que o ápice é reservado a uma elite branca $e$ a base a um imenso contingente de negros. No âmbito educacional, essa dicotomia revela-se mais violenta.

Dentre todos os espaços em que se vislumbram os efeitos do racismo, a educação aparece como o mais problemático. Dados surpreendentes confirmam a defasagem da população negra em relação à branca no que diz respeito à educação. Entre as crianças de 11 a 14 anos, do sexo masculino, pertencentes ao grupo dos $25 \%$ mais pobres do Brasil, por exemplo, $44,3 \%$ estavam, em 1999, cursando a segunda fase do $1^{\circ}$ grau. Entre os negros, esse percentual cai para $27,4 \%$. A conclusão é clara: os negros têm menos acesso à educação que os brancos no Brasil (Discurso do Deputado Federal Luiz Alberto, em 26/2/2003).

A cada dia fica mais evidente que a consciência da diversidade como valor positivo e emancipatório é apenas o primeiro passo para $\mathrm{o}$ atendimento às necessidades de diferentes grupos étnicos em diferentes espaços. Para além da consciência, é preciso envidar esforços que consigam promover a construção de uma democracia racial real, com iguais condições e oportunidades para todos. A quase inexistente população de afro-brasileiros como alunos das instituições de educação superior é prova inconteste da necessidade de reverter esse quadro de perversa seletividade.

Sobre a realidade exposta, felizmente temos verificado um movimento nacional intenso e diversificado, que vem apresentando propostas e ações afirmativas que buscam sua superação.

O governo federal, preocupado com a questão da desigualdade racial no país, promulgou a Lei 10.639/2003, que modifica a LDB no sentido de tornar obrigatórios os estudos sobre história e cultura afro-brasileiras nas escolas públicas e particulares de ensino fundamental e médio. Manteve, ainda, um programa do governo anterior ("Diversidade na universidade") que, por meio da Secretaria de Educação Média e Tecnológica (Semtec), em convênio com a Organização das Nações Unidas para a Educação, Ciência e Cultura (Unesco), financia organizações não governamentais que funcionam como cursinhos pré-vestibulares destinados a grupos socialmente desfavorecidos. Também criou a Secretaria Nacional de Promoção da Igualdade Racial, com status de Ministério, cuja titular visitou nossa capital durante o ano passado.

Também em 2003, o Conselho Nacional de Educação, numa iniciativa histórica, integrou, como conselheiros, educadores representantes dos movimentos de negros e índios.

Fortaleceram-se também a Fundação Palmares, que realizou seminário sobre ações afirmativas no Brasil no auditório do Banco da Amazônia (Basa), e o Centro de Estudos das Relações de Trabalho e Desigualdades (Ceert), que promoveu o seminário "Educando para a igualdade racial: promovendo e monitorando a igualdade racial no ambiente escolar" para educadores da região Norte, com o apoio deste 
Centro de Educação. A Associação Nacional de Pós-Graduação e Pesquisa em Educação (Anped), acompanhando essa tendência, criou o Grupo de Trabalho "Negro e Educação", para estimular pesquisas e propostas acerca do tema.

No dia 9 de dezembro de 2003 foi lançada, no Plenário da Comissão de Constituição, Justiça e Cidadania do Senado Federal, a publicação "Racismos contemporâneos", realização da Takano Cidadania e Ashoka Empreendedores Sociais que reúne um pouco da vasta produção crítica que vem sendo desenvolvida, na obscuridade, pelo conjunto da militância negra deste país. É isso que o livro representa: mais uma contribuição na direção da quebra do silêncio $e$ da invisibilidade a que tem sido historicamente submetida a crítica que o pensamento negro vem engendrando sobre as relações raciais no Brasil.

Entre os dias 3 e 5 de novembro de 2004, no Pará, sob a coordenação da Secretaria de Educação do Estado, realizou-se o Fórum Estadual de Educação e Diversidade Étnico-Racial, no auditório da Universidade da Amazônia.

Mais recentemente, o grupo de trabalho que elaborou a proposta de cotas para o processo seletivo 2005 da UFPA promoveu, no âmbito do Instituto de Ciências da Educação daquela universidade, um seminário sobre a Lei 10.639/2003, anteriormente mencionada.

Essa dinâmica tem favorecido ações políticas e socioeducativas que, além de combater o preconceito $e$ a discriminação, ajudam a promover a capacitação adequada para 0 fortalecimento do pluralismo cultural nas IES.

Foi nessa linha que se realizou, entre os meses de março e maio de 2004, na UFPA, uma pesquisa que buscou, basicamente, identificar qual a opinião da sua comunidade acadêmica sobre a questão racial $e$ a proposta de cotas no processo seletivo ${ }^{12}$. Após as perguntas fechadas acerca da proposta de cotas, os entrevistados justificaram sua posição com argumentos favoráveis ou contrários a ela. Do conjunto de argumentos contrários, detectamos argumentos baseados em diferentes concepções.

Em primeiro lugar, percebemos posições baseadas numa concepção "paternalista", sob a qual "a cota promove e aumenta o racismo, pois evidencia os limites dos negros, transformando-os em incapazes que só entram na universidade por causa da cota e não por sua competência".

Em segundo lugar, tivemos argumentos baseados na concepção de "mestiçagem", defendendo que "não se pode definir raça ou etnia, pois a miscigenação não permite que se determine quem é negro e quem não é, principalmente em nosso país, onde não é possível dizer quem é o quê."

Em terceiro lugar, ouvimos posições baseadas numa concepção "universalista", que argumenta que "não é dessa forma que se acaba com a discriminação, pois a mudança deve se dar a partir do aperfeiçoamento do sistema educacional, democratizando o acesso e melhorando a qualidade da educação básica".

Outra ordem de argumentos foi a que se fundamenta na concepção "meritocrática", para quem "todos são capazes, independentemente da cor, e o negro deve ingressar pelo seu esforço e mérito e não pela cor".

Semelhantes foram os argumentos baseados na concepção "classista", que menciona "as cotas como direito dos pobres como um todo e não de uma raça, o critério deve ser a necessidade e não a cor da pele".

\footnotetext{
${ }^{12} \mathrm{O}$ público pesquisado foi composto por estudantes dos cursos da UFPA que nela ingressaram desde o ano de 1996, sendo feitas cerca de 559 entrevistas com alunos dos 41 cursos existentes na UFPA. Tratou-se, portanto, de uma coleta aleatória, correspondente a $4 \%$ do total de seu corpo discente. Desde aquele período, por causa da escassez de recursos humanos e financeiros, os dados foram processados tendo em vista o encerramento de sua análise antes do mês de novembro de 2006, quando seriam divulgados por ocasião da semana da consciência negra. A maioria das entrevistas foi fechada, apresentando perguntas com alternativas predeterminadas. Todavia, a última pergunta era aberta e se referia ao argumento utilizado para justificar a posição favorável ou contrária à proposta de cotas para estudantes negros.
} 
Finalmente aludiu-se a argumentos baseados na concepção da "igualdade formal", sob a égide "da justiça para todos, pois a proposta privilegia somente alguns e todos são iguais perante a lei, portanto, os direitos devem ser os mesmos"13.

Como se vê, apenas esse trecho da pesquisa provocaria um debate sem precedentes, posto que o tema, embora de grande magnitude para a cidadania brasileira, continua pouco abordado e ainda altamente polarizado. $\mathrm{O}$ importante é que passos consideráveis foram dados.

A Justiça de Minas Gerais, em decisão histórica, determinou que doze centros de ensino superior daquele estado fossem obrigados a reservar $50 \%$ das vagas de todos os seus cursos a candidatos estudantes de escolas públicas. A procuradora que elaborou o parecer baseou-se justamente na premissa da "igualdade de oportunidades entre todos" prevista na Constituição e o direito de acesso "aos níveis mais elevados de ensino". Para ela, a reserva de vagas se justifica porque é "induvidosa a grande distância entre as condições fornecidas pelas escolas particulares no preparo daqueles que pretendem prestar o exame vestibular". Por seu turno, o procurador da república responsável pela ação comemorou a decisão, pois, para ele, "estudantes que deveriam ter primazia de acesso a tais instituições acabam excluídos em razão das deficiências do sistema público de ensino médio e fundamental e o ensino superior público, apesar de gerar um alto custo para a sociedade em geral, vem sendo usufruído quase exclusivamente por famílias de classe média e alta".

\section{A inclusão social como uma diretriz exten- sionista: a utopia como possibilidade}

Estudos sobre o desempenho acadêmico de estudantes beneficiados por políticas de ações afirmativas na Unicamp e na Uerj têm demonstrado claramente que os estudantes "conseguiram reduzir, igualar ou até superar a diferença que os separava dos demais no vestibular" ${ }^{14}$. Segundo o relatório da pesquisa na Unicamp, os dados referentes aos quatro primeiros semestres mostram que os beneficiados com pontos extras no vestibular por serem da rede pública têm médias melhores que os demais no curso. Importante destacar que essa situação ocorreu tanto nas carreiras de alta quanto nas de baixa relação candidato/vaga. No caso da Uerj, os números mostram que, ao ser avaliado o coeficiente de rendimento médio de todos os estudantes que ingressaram na universidade por cotas desde 2003, os beneficiados pela cota racial (para autodeclarados negros) ou pela reserva de vagas para a rede pública se saíram melhor do que os outros estudantes, além de apresentarem taxas de evasão menores.

No caso específico do curso de odontologia da Uerj - um dos mais concorridos —, da turma de 29 alunos que ingressaram em 2004, 14 eram cotistas e 15 não. Hoje já se pode afirmar que, dos 14 cotistas, 11 devem se graduar sem atraso com um CR médio de, até agora, 6,7 e, dos 15 não-cotistas, a expectativa é de que cerca de apenas 8 consigam se formar sem atraso, todavia com um CR maior $(8,0)$.

Um aspecto, contudo, foi essencial para esse êxito: as políticas de assistência estudantil, na perspectiva da permanência com sucesso dos estudantes em situação de vulnerabilidade socioeconômica, e o reforço acadêmico nos anos iniciais.

\footnotetext{
${ }^{13}$ UFPA. A questão racial na UFPA. Relatório da pesquisa. Centro de Educação, Belém, novembro de 2004

${ }^{14}$ FOLHA DE SÃO PAULO (Cotidiano), 30/09/07, p. C-4.
} 
Isso é tanto mais importante quanto necessário. A preocupação do MEC com a evasão de estudantes de nível superior levou-o a criar a Comissão Especial de Estudos sobre a Evasão nas Universidades Públicas Brasileiras em meados da década de 90 do século passado.

Os estudos dessa comissão demonstraram que cerca de $40 \%$ dos alunos que ingressavam na universidade abandonavam o curso antes de concluí-lo. Isso deixou claro que o sistema, além de ineficiente, tornava-se excessivamente caro. Um estudo da Sesu à época estimava que o custo com a evasão no sistema federal era de 486 milhões de reais ao ano, valor que correspondia a $9 \%$ do orçamento anual das instituições federais.

Resultado da investigação mencionada foi a certeza de que a apresentação de índices sobre evasão deve ser entendida tão somente como passo inicial de análises que devem buscar identificar e compreender os fatores que levam à evasão. Tais fatores podem ser de caráter interno às instituições específicas à estrutura e dinâmica de cada curso ou externo a eles, relacionados a variáveis econômicas, sociais, culturais, ou mesmo individuais que interferem na vida universitária dos estudantes (p. 136).

Segundo a comissão, tais fatores devem ser classificados em três ordens: em primeiro lugar, aqueles que se relacionam ao próprio estudante; em segundo, os relacionados ao curso e à instituição; finalmente, os fatores socioculturais e econômicos externos (p. 137).

Dentre estes últimos, destacam-se os:

- relativos ao mercado de trabalho;

- relacionados ao reconhecimento social da carreira escolhida;

- afeitos à qualidade da escola de primeiro e segundo graus;

- vinculados a conjunturas econômicas específicas;

- relacionados à desvalorização da profissão, por exemplo, o "caso" das licenciaturas;

- vinculados a dificuldades financeiras do estudante;
- relacionados às dificuldades de atualizar-se a universidade diante dos avanços tecnológicos, econômicos e sociais da contemporaneidade;

- relacionados à ausência de políticas governamentais consistentes e continuadas voltadas ao ensino de graduação (p. 139).

Portanto, para fazer frente aos problemas identificados, a comissão sugere, dentre outras, as seguintes medidas:

- oferecer atividades de apoio pedagógico a estudantes com dificuldade no ensino;

- melhorar a formação pedagógica do docente universitário;

- estabelecer mecanismos de apoio psicopedagógico ao estudante;

- criar ou ampliar programas de bolsas acadêmicas;

- ampliar programas de convênios para estágios dos estudantes em empresas, escolas etc;

- desenvolver programas de cultura e lazer nas instituições universitárias;

- ação pedagógica organizada em disciplinas com altas taxas de reprovação;

- produção de material de divulgação, para os estudantes de ensino médio, a respeito do perfil dos cursos e das possibilidades de profissionalização a eles vinculadas (p. 141).

Atualmente, uma simulação da taxa de conclusão de cursos de graduação a partir dos dados da PingIFES (Plataforma de Integração de Dados das Ifes) 2005 por curso de graduação demonstra que a média nacional é de cerca de $63 \%$, mantendo o índice do século passado praticamente intocável. Quanto à UFPA, a quantidade de ingressantes é de 5811 estudantes e de concluintes, 4109 estudantes, perfazendo uma taxa de conclusão de $70,71 \%$. No contexto das 50 Ifes brasileiras, é interessante notar que, em termos de taxa de conclusão, a UFPA situa-se em $15^{\circ}$ lugar. Todavia, em relação ao número de ingressantes, fica em $3^{\circ}$ lugar e, no que tange ao número de concluintes, é a que mais gradua no país. 
Por outro lado, em 19 de outubro deste ano, o Conselho Universitário, numa decisão histórica, aprovou a adesão da UFPA ao Programa de Apoio a Planos de Reestruturação e Expansão das Universidades Federais (Reuni), medida que consolidará nosso processo de expansão como maior universidade federal brasileira em número de alunos.

Em que pese esse dado positivo, para se constituir em uma dimensão importante no âmbito da UFPA, a política de assistência estudantil deverá converter-se em um conjunto de ações que tenham em vista a integração acadêmica, científica e social do estudante, incentivando-o ao exercício pleno da cidadania e promovendo seu êxito acadêmico. Para tanto, aproximarse do cotidiano do estudante em situação de vulnerabilidade é essencial, pois é nele que os riscos de insucesso acadêmico se manifestam e se constituem de forma mais definitiva.

\section{Conclusões}

Ensino, pesquisa e extensão são, classicamente, os três pilares da universidade pública brasileira. Entretanto, enquanto os dois primeiros são campos consagrados e bem consolidados, a extensão continua objeto de controvérsias. Por vários anos, a academia entendeu a extensão apenas como uma forma de prestação de serviços à sociedade, com enfoque no caráter assistencialista da ação. Depois de muitos de- bates e experiências acumuladas, esse conceito está mudando. Hoje, extensão é, principalmente, troca de saberes entre a academia e a sociedade. É, portanto, um processo de aprendizagem mútua.

As transformações ocorridas na gestão da extensão exigem agora da universidade a instalação de dinâmicas de acompanhamento $e$ avaliação das suas ações, a partir de um processo permanente de registro e controle pelas unidades acadêmicas e de uma nova lógica de significação das ações baseada na vinculação orgânica da extensão às atividades de ensino, posto que a UFPA coloca como desafio até 2009 institucionalizá-la por meio dos projetos pedagógicos dos cursos de graduação, em atendimento à Meta 23 do Plano Nacional de Educação ${ }^{15}$, em cumprimento ao seu novo regulamento da graduação. Tais marcos têm desafiado a UFPA, seus docentes, discentes e técnicos, no sentido de institucionalizar a vivência de ações extensionistas como síntese do fazer universitário $e$ da realidade social, questionando o seu papel e redimensionando-o rumo a uma atuação mais eficaz na sociedade.

Por outro lado, é essencial compreender que a dimensão inclusiva da extensão, manifesta na consolidação das políticas de assistência estudantil, ainda é um desafio cuja superação apresenta naturezas diversas (de proteção, de diversidade, de sensibilidade e de inovação), afinal, seu fortalecimento como dimensão estratégica representa, sem dúvida, uma real contribuição para a retomada da democracia $e$ da cidadania em nosso país.

\section{REFERÊNCIAS}

GOMIDE, Denise (Org.). Governo e sociedade civil: um debate sobre espaços públicos democráticos. São Paulo: Abong, 2003.
GONH, Maria da Glória. Movimentos sociais no início do século XXI: antigos e novos atores sociais. Petrópolis/Rio de Janeiro: Vozes, 2003.

\footnotetext{
${ }^{15}$ A meta 23 do Plano Nacional de Educação é "Implantar o Programa de Desenvolvimento da Extensão Universitária em todas as Instituições Federais de Ensino Superior no quadriênio 2001-2004 e assegurar que, no mínimo, 10\% do total de créditos exigidos para a graduação no ensino superior no País será reservado para a atuação dos alunos em ações extensionistas".
} 
DAMASCENO, A. et al. A política da extensão como pedagogia da sensatez...

UNIVERSIDADE FEDERAL DO PARÁ. Pró-Reitoria de Extensão. Anteprojeto da política de assistência estudantil. Belém: UFPA, dezembro/2007.
UFPA, Centro de Educação. Relatório da pesquisa sobre a questão social na UFPA. Belém: UFPA, novembro/2004.

Texto recebido em 15 de janeiro de 2007.

Texto aprovado em 22 de setembro de 2008. 